\title{
Preschoolers, Parents, and Teachers (PPT): A Preventive Intervention with an At-Risk Population
}

\author{
Kay Draper \\ Christine Siegel \\ Fairfield University, csiegel@fairfield.edu \\ Joanna White \\ Caroline M. Solis \\ Faye Mishna
}

Follow this and additional works at: https://digitalcommons.fairfield.edu/education-facultypubs 2009. Copyright Guilford Press. Reprinted with permission of The Guilford Press.

\section{Peer Reviewed}

\section{Repository Citation}

Draper, Kay; Siegel, Christine; White, Joanna; Solis, Caroline M.; and Mishna, Faye, "Preschoolers, Parents, and Teachers (PPT): A Preventive Intervention with an At-Risk Population" (2009). GSEAP Faculty Publications. 55.

https://digitalcommons.fairfield.edu/education-facultypubs/55

\section{Published Citation}

Draper, K., Siegel, C., White, J., Solis, C.M., \& Mishna, F. (2009). Preschoolers, Parents, and Teachers (PPT): A Preventive Intervention with an At-Risk Population. International Journal of Group Psychotherapy, 59(2), $221-242$.

This item has been accepted for inclusion in DigitalCommons@Fairfield by an authorized administrator of DigitalCommons@Fairfield. It is brought to you by DigitalCommons@Fairfield with permission from the rightsholder(s) and is protected by copyright and/or related rights. You are free to use this item in any way that is permitted by the copyright and related rights legislation that applies to your use. For other uses, you need to obtain permission from the rights-holder(s) directly, unless additional rights are indicated by a Creative Commons license in the record and/or on the work itself. For more information, please contact digitalcommons@fairfield.edu. 


\title{
Preschoolers, Parents, and Teachers (PPT): A Preventive Intervention with an At risk Population
}

\author{
KAY DRAPER, PH.D. \\ CHRISTINE SIEGEL, PH.D. \\ JOANNA WHITE, ED.D. \\ CAROLINE M. SOLIS, PH.D. \\ FAYE MISHNA, PH.D.
}

\section{ABSTRACT}

The importance of early intervention with children who are at risk for mental health problems is widely recognized. Relationships with significant adults (parents, other caregivers, and teachers) are critically important in young children's lives and can make a tremendous difference in the trajectory of a child's future. This study utilized a waiting-control group design to examine the ef fects on student behavior and parent stress of play-based interventions designed to improve the relationships between parents and their children (i.e., Filial Therapy), and teachers and their students (i.e., Kinder Training). To incorporate the benefits of group work, the eight-week intervention was delivered to parents in a small-group format. Teachers participated in a one-day group

\footnotetext{
Kay Draper, Ph.D., and Christine Siegel, Ph.D., are former assistant professors at Georgia State University in the Department of Counseling and Psychological Services (CPS) in the College of Education. Christine Siegel is currently a member of the faculty at Fairfield University, Fairfield, Connecticut.JoAnna White, Ed.D., is Professor and Chair of the CPS department from which Caroline Solis, Ph.D., recently completed her doctorate in school psychology. Faye Mishna, Ph.D., is Associate Dean of Research and Associate Professor and holds the Margaret and Wallace McCain Family Chair in Child and Family at the Factor-Inwentash Faculty of Social Work at the University of Toronto.

This study was funded by a grant from the Rockefeller Brothers Fund under the auspices of the American Group Psychotherapy Association. We would like to thank Liz Lambert for her assistance with the manuscript and Dianne Feirman and Marsha Block for their overall support.
} 
training with weekly coaching and dyadic consultation for on-going support. Results at post-intervention indicated that teachers perceived children in the intervention group to exhibit significantly less problem behavior than students in the waiting-control group. Although results suggest that the intervention had no demonstrable effect on parent stress, qualitative results indicate otherwise. Implications for practice and research are discussed.

We are all social beings who are born into a family, our first group. Sooner or later, we expand our world by becoming part of another group, typically at day care or school. From the beginning, how we interact with the significant people surrounding us impacts our personality development and future endeavors. These early relationships, along with our interpretations of our interactions with others, exert a great influence over who we become (Bowlby, 1988; Ferguson, 1984). Significant adults in the lives of young children (typically parents, other primary caregivers, and teachers) possess the ability to engage children in ways that either contribute to the strength and resiliency of, or conversely, the vulnerability and risk of those in their care. Developmental psychologists (e.g., Ainsworth, 1973; Bowlby, 1988; Early et al., 2007; Pianta, 1999) assert that high quality interactions between a significant adult and child lead to more hopeful outcomes for the child. School maladjustment and dropout, drug use, risky sexual behavior, criminal activity, and poor mental health are some of the negative outcomes associated with children who do not have the benefit of strong healthy relationships with significant adults (Barr \& Parrett, 2001, Brazelton \& Greenspan, 2000; Garbarino, 1999; Pianta, 1999).

While positive relationships with adults are important in the lives of all children, they may be particularly valuable for children who are more vulnerable as a result of their environmental circumstances (Armstrong, Birnie-Lefcovitch, \& Ungar, 2005). Due to factors such as racism, oppression, socioeconomic status, and poor living conditions, some children are faced with more potent challenges to their well being over the short and long term. Psychologists and psychotherapists agree that as the number of risk factors increases, the likelihood of mental health problems and 
school maladjustment in the life of a child also increases. However, theory and research in the area of resiliency purports that children considered "at risk" can develop the ability to survive and thrive in spite of difficult life circumstances if specific protective factors such as caring relationships are also present (Egeland, Carlson, \& Sroufe, 1993; Goldstein \& Brooks, 2006). In this study, caring relationships are fostered between preschooler and parent as well as between preschooler and teacher in order to determine if a potentially strong protective factor could be encouraged. The purpose of the current study was to examine the effects on student behavior and parent stress of play-based interactions between parents and their children (i.e., Filial Therapy) and teachers and their students (i.e., Kinder Training). The students in the study were considered broadly at risk for future school and mental health problems. Consequently, the project was preventive in nature. The two-pronged intervention was designed to enhance parent-child and teacher-child relationships and strengthen the competencies of preschoolers, their parents, and their teachers.

\section{FILIAL THERAPY}

Filial Therapy is a form of therapy that enhances the way parents play with their children in order to strengthen this potentially protective relationship. Child's play has cognitive, physical, social, and emotional benefits that are indisputable. Play "is the most natural way for the child to use his capacities, to grow, and to learn many skills" (Caplan \& Caplan, 1973, p. xii). It stands to reason that the use of therapeutically informed play is an effective way through which to connect with a child (Landreth, 2002). This assertion is a primary basis for the field of play therapy. Melanie Klein and Anna Freud were pioneers in using play with children in therapeutic settings (Gil, 1991). Later, Virginia Axline (1947) developed play therapy as we know it today, a developmentally appropriate intervention that burgeoned into a specialty area of mental health.

In the 1960's, Guerney (1964) proposed, and later demonstrated, a parent could be trained as a therapeutic change agent. Through therapeutically informed play, a parent could meet the 
child's psychological needs while simultaneously strengthening the parent-child relationship. Guerney and Guerney (1988) developed and researched Filial Therapy with groups of parents. By meeting with parents in groups to (a) teach the client-centered skills of the approach and (b) process the parent-child play sessions that occurred, Guerney and Guerney relied on the power of group work to create change in the parents. The therapeutic factors at work in these parent groups include: (a) opportunities for vicarious learning as members witness each other practicing skills and talking about their lives, (b) the support group members receive from one another as they share their stories, (c) the universality experienced as parents realize their similarities, and (d) the catalytic effect that occurs when a group member's development is pushed by the growth another member experiences (Gladding, 2003; Yalom \& Leszcz, 2005). The skills taught to parents in Filial Therapy include letting the child take the lead in the play and following rather than directing the play; setting limits only when needed and with a calm demeanor that offers choices to the child about behaviors; reflecting back what the child is saying without offering opinions or judgments; and responding empathically to the child's expressed feelings rather than imposing parental views by giving advice or being dismissive. Guerney and Guerney (1988) concluded that Filial Therapy was generally effective in reducing child problems and increasing parental acceptance of the child (Guerney \& Stover, 1971; Sywulak, 1977). In a comprehensive follow-up study, therapeutic gains at termination of treatment were maintained for at least three years (Sensue, 1981).

Research suggests that Filial Therapy has the potential to improve parental acceptance of the child, increase parental empathic responding, and decrease parent-reported child behavior problems. Filial Therapy has been successful with children with learning disabilities (Guerney, 1979; Kale \& Landreth, 1999), chronically ill children (Tew, Landreth, Joiner, \& Solt, 2002), foster/adoptive parents (Guerney \& Gavigan, 1981), and incarcerated parents (Harris \& Landreth, 1997; Landreth \& Lobaugh, 1998). In a meta-analysis of general play therapy outcomes, LeBlanc and Ritchie (2001) found a treatment effect size of .60 that was strengthened by parental involvement in the play therapy 
process. In another meta-analysis, Bratton, Ray, Rhine andjones (2005) found a large effect size for play therapy interventions (.80), with the largest effects when parents were included in treatment. Thus, Filial Therapy is a well supported play-based intervention that can be productive in helping the child, strengthening the parent-child relationship, and enhancing parenting skills (Landreth \& Bratton, 2006).

Compared to other parenting interventions, an important advantage of Filial Therapy is that the design is encouraging and empowering to parents because it asks parents to make specific changes only during the once weekly play sessions. That is, parents are not asked to change their parenting across all interactions with their children, which could be quite overwhelming. Filial Therapy asks parents to practice new skills such as following their child's lead, setting limits calmly and giving choices, paraphrasing and responding empathically, all during 30-minute play sessions conducted once a week. Experiences during these weekly play sessions are discussed during weekly parent group meetings. Over time, with group encouragement, skills initiated during play sessions become part of the parenting repertoire (Landreth \& Bratton, 2006).

\section{KINDER TRAINING}

Kinder Training, an adaptation of Filial Therapy, is a play-based intervention designed to assist teachers in their efforts to develop positive relationships with students in the classroom. Kinder Training grew from an early extrapolation of Filial Therapy described by Guerney and Stover (1971). Since parents were being trained effectively as therapeutic change agents for their own children, the authors decided to train teachers to conduct play sessions with students.

White, Flynt, and Draper (1997) built on the early work of Guerney and Stover to develop an approach for training teachers in basic play therapy skills in combination with concepts of Adler's Individual Psychology, often used in school settings. These concepts include the use of encouragement and the view of the goals of misbehavior as need for attention, power, revenge, and 
withdrawal. In learning to connect with one child in a play-based setting, teachers have the opportunity to strengthen their understanding of a troubled student and strengthen their relationship skills. Based on the premise that teachers would generalize skills for intervening with one child to their approach to behavior management in the classroom, Kinder Training was developed as a consultative intervention whereby school counselors could effect change for large numbers of students. Thus, the purpose of this approach was to assist teachers in redirecting child misbehavior while simultaneously creating positive classroom climates. The first application of Kinder Training involved introducing basic play therapy skills to one classroom teacher, to help her build a relationship with a child struggling behaviorally and academically. The anecdotal success of this brief intervention was impressive.

Subsequent research (White, Flynt, \& Jones, 1999; Draper, White, O'Shaughnessy, Flynt, \& Jones, 2001) provided empirical support for Kinder Training. Students evidenced increases in adaptive behavior, decreases in problem behaviors, and improvement in early literacy skills; teachers demonstrated increases in their use of effective statements for encouragement and limitsetting in the classroom. Though Kinder Training requires additional empirical support to establish its efficacy, preliminary evidence suggests that the approach has been well received by teachers and students. Teachers seem to benefit from developing play-based relationships with students about whom they are concerned. Children are better supported in the classroom when teachers have taken the time to get to know them in a setting where the children are comfortable.

\section{PRESCHOOLERS, PARENTS, AND TEACHERS (PPT)}

The Preschoolers, Parents, and Teachers (PPT) project was a two-pronged intervention that provided Filial Therapy groups to parents of preschoolers while at the same time conducted Kinder Training with the teachers of those preschoolers. During an eight-week intervention period, parents and teachers of the preschool children were trained and asked to practice newly learned 
skills with the children in the home and school settings, respectively. Parent training occurred in ongoing weekly groups so that the benefits of group work might influence participant learning. Teachers were trained together in a group of 12 and then provided on-going support in dyads. The purpose of the intervention was to strengthen the relationships between the preschoolers and the significant adults in their lives in order to bolster the competencies of the children and the adults. That is, while the children received the benefit of positive play-based interactions with their parents and teachers, the parents and teachers potentially gained new skills that enhanced their abilities to parent or teach children in their care. The main purpose of this study was to examine the effects of this training and the subsequent play-based interactions on the preschoolers. We also considered the potential effects of the training on the preschoolers' primary caregivers. Specific questions asked were: 1) Does participation in the PPT project decrease behavior problems in preschool students from an at risk population? 2) Does participation in the PPT project facilitate social competence in preschool students from an at risk population? and 3) Does participation in the PPT project alleviate stress related to parenting for parents or primary caregivers of preschoolers from an at risk population?

\section{METHOD}

\section{Context}

The PPT project was conducted during the 2003-2004 school year at two elementary schools in a large, urban school district in the southeastern United States. Nearly all (99\%) of the approximately 500 students at each school were African American and a vast majority of the families lived in poverty. Each school housed students in preschool through fifth grade, with two preschool classrooms ( $\mathrm{n}=35$ students) at one school and four preschool classrooms ( $\mathrm{n}=69$ students) at the other. Preschool class sizes ranged from 16 to 18 students, with a lead teacher and a paraprofessional aide in each classroom. 


\section{Participants}

Preschoolers. Participation in the PPT project was offered to all parents of preschool children at the two participating elementary schools. The parents of 60 students (58\% of the total preschool population) agreed to participate. Participating students ranged in age from four years (i.e., 49 months) to five years (i.e., 61 months) and included an equal number of boys and girls. The majority (73\%) lived in homes with two or more adults and two or more children. With the exception of one student for whom race/ethnicity was not specified, all participating preschoolers were identified as Black/African American by their parents.

Participating students were randomly assigned to treatment and waiting-control conditions by classroom. Three classrooms were designated to participate in the intervention during the fall semester, while three classrooms waited to receive intervention in the spring. At the start of the project, there were 28 students in the treatment condition and 32 in the control condition. As the total sample was demographically homogeneous, no significant demographic differences were assumed between students in the treatment and control groups.

Parents. For each participating preschool student, one primary caregiver (i.e., parent or individual acting in the role of parent) participated in the project. Primary caregivers provided demographic information about themselves and their participating child by completing the Parent Appraisal of Children's Experiences (PACE 2.0, 2002). While most (51) of the participating parents were mothers, the sample also included 5 fathers and 4 grandmothers. Mothers ranged in age from under 21 years to over 39 years, with a median age of 25 to 29 years. The median age of fathers was likewise 25 to 29 years. The majority of parents (9 I\% of mothers and $80 \%$ of fathers) had completed high school, with some (27\% of mothers and $5 \%$ of fathers) having completed four-year college degrees.

Teachers: Lead teachers $(n=6)$ and paraprofessional aides $(n=6)$ from each classroom participated in the project. The teachers and paraprofessionals represented a wide range of experience, having taught from just a few years to almost 30 years. All teachers and paraprofessionals were African American women. 


\section{Intervention}

Parents. The parent component of the intervention was based on Filial Therapy models developed by Bernard and Louise Guerney (1988) and Garry Landreth (1991). The parent intervention also incorporated elements of effective discipline based on Adlerian Individual Psychology, including understanding parenting styles, distinguishing encouragement from praise, identifying the g9als of children's misbehavior, and implementing logical consequences.

For purposes of the intervention, parents met together in small groups for two-hour sessions held at the elementary schools once per week for eight weeks. Each group was facilitated by an experienced counselor or graduate student well trained in the concepts of group process, play therapy, Filial Therapy, and Individual Psychology. Additionally, each group included a co-facilitator to assist with logistics and group process. Co-facilitators included practicing school counselors, school psychologists, professional counselors, and graduate students. Some of the co-facilitators were trained in group process, play therapy, and/or individual psychology. Due to the potential impact of culture on both parenting and group process, at least one of each group's facilitators was African American.

During the sessions, the parents were taught child-centered and Adlerian play therapy principles and techniques to be utilized in weekly, 30-minute play sessions with their child. The acronym TEEL was used to help parents remember these strategies: tracking ( $T)$, empathy $(E)$, encouragement (E), and limit setting (L). Tracking involves communicating in a nonjudgmental manner what the children are doing and saying; empathy involves acknowledging the children's feelings. Together they help children feel understood, listened to, and important. Encouragement is the active process of focusing on children's strengths, abilities, and resources; it is distinctly different from praise in that it emphasizes a child's effort, not outcome. Finally, parents were taught a specific way of setting limits that was respectful, clear, and firm.

Prior to beginning play sessions at home, parents attended two training sessions. These training sessions included a combination of didactic instruction, modeling via video tape, and role 
playing. In these early sessions, parents were asked to reflect on their hopes for their child and for their relationship which stimulated a great deal of discussion. They talked about wanting their children to be happy and wanting to have a strong relationship with them. The leaders emphasized that a way to achieve these hopes was through better understanding their children which therapeutically informed play could foster. In subsequent training sessions, parents were asked to reflect on and share what happened during play sessions, what their thoughts and feelings were during the session, what their child's reaction to the play time was, and what problems were encountered. For the most part, the parents felt they were able to relax during the play sessions, and many stated that through the play they learned things about their children that they had not previously known. They reported that their children looked forward to their next play sessions and they felt good that the children valued having the play time with them. Teaching points (e.g., discipline versus punishment, goals of misbehavior, how to use natural and logical consequences) were incorporated in the third through seventh training sessions. During the eighth and final session, parents reflected on what they had learned about themselves and their child as a result of engaging in the intervention. As an example, one parent said that she had previously considered herself to be a good parent, doing all of the things good parents are supposed to do, such as feed, clothe, and discipline her child. After this mother began the play sessions, she realized how much deeper good parenting went, including hearing her child's feelings, and encouraging her child. Additionally, parents were asked to consider ways in which they could sustain the play times with their child beyond the end of the group sessions and to continue to conduct two play sessions at home following the conclusion of the parent group.

Teachers. The teacher component of the intervention was based on the Kinder Training model developed by White and colleagues (1997) and supported by additional studies (White et al., 1999; 2003). Teacher intervention included a one-day training session followed by weekly in-class support. Initial training was provided by two of the developers of Kinder Training, both of whom were counselor educators. Ongoing support was provided by classroom coaches, who included the Kinder Training devel- 
opers, and a graduate student/practicing school psychologist with extensive knowledge of play therapy, individual psychology, Filial Therapy, and Kinder Training.

Lead teachers and paraprofessional aides from both schools met together to attend the one-day training session, which included didactic instruction, modeling via videotape, and role-playing in the classroom. Additional training participants included preschool administrators, preschool family service workers, and members of the research team. The didactic portion of the training consisted of (a) introductory activities, (b) an overview of the basic philosophy and purposes of Kinder Training, (c) important concepts from Adlerian psychology, and (e) specific play therapy skills such as tracking, empathizing, encouraging, and limit setting. Teachers were taught the importance of play for healthy child development as well as the importance of taking a nondirective stance (e.g., avoiding asking questions and leading the child's play), and of being nonjudgmental and respectful. Consistent with the parent training, teachers were taught the acronym TEEL to remember specific play therapy strategies which were demonstrated through videotape. Following the didactic portion of the training session, teachers and trainers role-played using the play therapy skills and language in the classroom. Teachers were asked to implement the play therapy skills in their classrooms during special 30-minute play sessions. These sessions were implemented once per week for eight weeks during a nonteacher directed time (e.g., center time, during which children have activities from which to choose at different tables or areas of the room). During these weekly special play times, a coach was present in the classroom to provide teachers with modeling, encouragement, coaching, and feedback. Unfortunately, due to constraints in the school setting, it was not possible to have the teachers meet in an ongoing group format.

\section{Measures}

Student Behavior. To measure the effect of the PPT intervention on preschool student behavior, participating teachers completed the Behavior Assessment System for Children - Teacher Rating Scale (BASC-TRS; Reynolds \& Kamphaus, 1992). Designed to 
measure both problematic behaviors and social competencies exhibited by students in school settings, the BASC-TRS comprises a series of descriptions of student behavior (e.g., nail biting; hitting; distractability; cries easily) rated on a four-point Likert scale. Teacher ratings are converted into $\mathrm{T}$-scores $(\mathrm{M}=50$; $\mathrm{SD}=$ 10) for interpretation.

The BASC-TRS preschool form, administered to teachers of students aged four to five years, yields composite scores for overall problem behavior (i.e., Behavior Symptoms Index), and prosocial behavior, (i.e., Adaptive Skills). The Behavior Symptoms Index (BSI) includes measures of aggression (e.g., verbally or physically hostile behavior), hyperactivity (e.g., high levels of activity), anxiety (nervousness, fearfulness, or worry), and depression (e.g., state of unhappiness that interferes with the student's ability to participate in daily activities). Above-average scores on these scales indicate that a student is experiencing significant levels of social-emotional difficulty that are likely to interfere with his/her ability to adjust to and succeed in school.

At the preschool level, the Adaptive Skills (AS) composite comprises measures of adaptability (i.e., the ability to adjust to environmental changes) and social skills (e.g., skills for relating to parents, teachers, and other students). Above-average scores on these scales indicate the student possesses the social competencies to adapt to routines and relate to others, which can facilitate school success and maintain mental health. The BASC-TRS preschool form provides adequate reliability (e.g., average internal consistency $=.82$, median test-retest reliability $=.89$ ). Factor analytic methods provide support for the construct validity of the instrument (Reynolds \& Kamphaus, 1992). For each student in the sample, participating teachers completed the BASC-TRS twice, one week prior to the start of the PPT intervention and two weeks subsequent to the conclusion of the play sessions with parents and teachers.

Parent Stress. To measure the effect of the PPT intervention on parent stress, participating parents completed the Parent Stress Index - Short Form (PSI-SF; Abidin, 1995). Developed on the theory that overall parenting stress is a function of the combination of child characteristics, parent characteristics, and the interaction between child, and parent, the PSI-SF yields a composite 
score (i.e., Total Stress) and three scale scores (i.e., Difficult Child, Parent Distress, and Parent-Child Dysfunctional Interaction). A self-report measure, the PSI-SF contains 36 Likert-type items to be rated by parents of children aged three to twelve years. Item ratings are converted to percentile rank scores for interpretation.

A confirmatory factor analysis supports the three-factor structure of the instrument, which provides adequate reliability (Abidin, 1995). In order to further assess the psychometric adequacy of the PSI-SF, independent investigators (Reitman, Currier, \& Stickle, 2002) administered the instrument to a group oflower socio-economic, primarily African-American mothers of preschool children. Results indicated that PSI-SF scores were consistent with parent reports of self, child and environmental stressors, leading researchers to conclude that this measure is appropriate for use with populations similar to those participating in the current project. Parents who participated in the PPT intervention completed two administrations of the PSI-SF, corresponding to the time period for teacher data collection.

\section{Analyses}

Prior to analyses, the data were edited for accuracy, with cases deleted for one of two reasons. First, in order to be retained as a member of the treatment group, parents of participating students were required to attend at least four of the eight parent group training sessions, with one of those four being either the first or second session. Second, when it was discovered that one of the teachers in the control group did not complete the BASC-TRS according to standard procedures for administration, students in this teacher's classes were removed. Additional attrition from the original sample was due to family relocation to other school systems. Forty-two students were retained in the final database.

\section{RESULTS}

Student Behavior. A one-way MANOVA was calculated to determine the effects of condition assignment (i.e., treatment or control) on post-test measures of student problem behavior (BASC- 
TABLE 1. BASCTRS Scores

\begin{tabular}{|c|c|c|c|c|c|}
\hline & & \multicolumn{2}{|c|}{ Behavior Symptoms Index (BSI)a } & \multicolumn{2}{|c|}{ Adaptive Skills (AS)b } \\
\hline & & Pre-test & Post-test & Pre-testt & Post-tes \\
\hline Condition & $\mathrm{n}$ & $\mathrm{M}(\mathrm{SD})$ & $\mathrm{M}(\mathrm{SD})$ & $\mathrm{M}(\mathrm{SD})$ & $\mathrm{M}(\mathrm{SD})$ \\
\hline Treatment & 22 & $54(9.1)$ & $57(10.4)$ & $42(8.9)$ & $43(9.3)$ \\
\hline Control & 18 & 55 (7.6) & 65 (6.6) & $44(6.2)$ & $44(4.8)$ \\
\hline
\end{tabular}

'The average range for BSI scores is from 41 to 59. Scores between 60 and 69 are in the "at-risk" range, scores 70 and above are "clinically significant." "The average range for AS scores is from 41 to 59.

TRS BSI) and social competence (BASC-TRS AS). A significant effect was found $($ Lambda $(2,38)=.797, p=.013)$.

Follow-up repeated measures ANOVA revealed a significant Timex Condition interaction $(\mathrm{F}(1,38)=15.667, p<.001)$, as well as a main effect for time $(\mathrm{F}(1,38)=54.499, p<.001)$ on measures of problem behavior. Examination of BASC-TRS BSI data (Table 1) revealed no difference between the treatment and control condition at the time of pre-test, with mean scores for both conditions falling in the average range. An increase in the problem behavior of students in the waiting-control condition from pre-test to post-test was noted, with the mean waiting-control condition BSI score falling solidly in the at risk range at post-test. These results suggest that the externalizing and internalizing behaviors of students who did not receive the intervention increased to levels that interfere with school adjustment. In contrast, during the time between pre-test and post-test, the problem behavior of students in the treatment condition remained stable and within the normal range for preschool students.

For measures of social competence, neither the main effects for time $(p(1,38)=.243, p>.05)$ or condition $(F(1,38)=.149, p>$ $.05)$ nor their interaction $(\mathrm{F}(1,38)=.696, p>.05)$ were significant. Review of BASC-TRS AS scores (Table 1) revealed no significant differences between the two conditions at the time of pre-test, with scores for both conditions in the average range of functioning. Likewise, at the time of post-test, mean scores for both conditions remained in the average range, with no significant differences between conditions.

Parent Stress. A 2 × 2 mixed design ANOVA was calculated to examine the effects of condition assignment (i.e., treatment and 
TABLE 2. PSI..SF Total Scores

\begin{tabular}{lccr}
\hline Group & $\mathrm{n}$ & Pre-test & Post·test \\
\hline Treatment & 22 & $M(S D)$ & $M(S D$ \\
Control & 16 & $31(27.0)$ & $37(29.5)$ \\
\hline
\end{tabular}

Note. The average range for PSI-SF Total Stress scores is 15 to 8.5 . Scores between 30 and 40 indicate low-average levels of parenting stress.

waiting-control) and time (pre-test and post-test) on parent stress as measured by the PSI-SF Total Score. No significant effects were obtained. Examination of the PSI data (Table 2) revealed that parents in both the treatment and control conditions reported low levels of overall stress related to parenting at both the beginning and end of the intervention period.

\section{DISCUSSION}

Consistent with the goals of a preventive intervention, the current results demonstrated that the problem behaviors of students whose parents and teachers did not participate in the intervention increased, while the behavior of participating students remained stable. The current results suggest that without the intervention, students in the treatment condition might have likewise demonstrated an increase in behaviors such as aggression, hyperactivity, anxiety, and depression that could negatively influence their adjustment to school, including their ability to learn, peer relations, and sense of themselves as learners.

While the intervention may have served to prevent the development of maladaptive behavior among participating students, it seemed to have no demonstrable effect on adaptive behavior as it was measured. When interpreting this finding, it is important to remember that participating students at the start of the study were identified as at risk for developing, but not actually demonstrating, below average levels of adaptive behavior. With consideration to the demonstrated effect on problem behavior, this finding suggests that attention, empathy, encouragement, and appropriate limits from parents and teachers are more effective in maintaining appropriate types of interpersonal interaction, average levels of activity, and stable emotional states than 
they are in raising social skills above developmental expectations for preschool students.

In addition to examining the intervention's effect on preschool student behavior, the current study examined the impact of PPT on parent stress. Results suggest that the intervention had no demonstrable effect on parent stress as measured by the PSI-SF. There are several possible interpretations of this finding. First, it is interesting to note that the vast majority of the parents' responses on the PSI indicated that they were experiencing little to no stress related to parenting at the start of the intervention. While it is possible that these parents were simply not experiencing much stress related to parenting at that time, it also seems possible that parents were not comfortable sharing their actual feelings about parenting on the self-report measure. Possibly too, there may have been a sampling bias such that high stress parents chose not to participate in the study. Often parents come to school with their own feelings, sometimes negative, about what school was like for them growing up. These feelings make them hesitant and perhaps a little suspicious of those affiliated with the school and defensive in their actions. Another possibility is that parents who completed this measure had not had much opportunity to reflect on their experiences as parents and what it meant to be a parent. One group member, who began her group sessions stating very confidently that she would not change anything about her parenting, shared after a few weeks of group that she realized that her role as a parent went much deeper than she had previously considered. Having the opportunity to reflect on herself as a parent as well as to know her child better, she began to see how important her parenting was as an influence on her child. Finally, while the PSI-SF has been validated for use with African-American preschool parents, it is possible that the instrument was not sensitive to the types of stress that parents in the current study experienced. Preliminary analysis of qualitative data from interviews with a subset of the participating parents (manuscript in preparation) suggests that in general they felt calmer, more competent, and more assured in their role as parent after the intervention.

The PSI was administered because it was assumed that the parents of preschoolers, especially preschoolers who were broadly 
considered at risk would be experiencing some stress. While the results of this measure would lead one to believe that they were not, anecdotal and other evidence suggested that, indeed, they were. During interviews, parents described a variety of difficulties associated with parenting, including managing their children's behavior, maintaining a balance between multiple roles, and providing for their children's needs with limited resources. During debriefing interviews, nearly all of the parents described feeling validated by the group process which helped them recognize that other parents confronted similar difficulties in parenting. Additionally, they described continuing to use skills taught in the group sessions even after the sessions had ended, and theyreported that the skills were useful in addressing difficulties they experienced. For example, many described using limit setting, as an alternative to yelling or threatening, when addressing their children's misbehavior. One parent described using tracking as a method to maintain her own patience and balance. Finally, many parents reported that the use of empathy enhanced their relationships with others in general and helped them define their relationship with their preschool child in particular.

While the measurable positive impact of this study was on the children, the parents who participated in their training in a group format seem to have received the support and skills necessary to maintain the absence of problem behaviors in their children. Qualitative interview data suggest that group members appreciated the positive effects of learning together and supporting each other in their roles as parents (manuscript in preparation). For example, group members who had not previously known each other reported becoming friends and turning to each other for support regarding their parenting.

The most important quantitative finding of this study is that this intervention prevented the children in the treatment condition from a downward trend in their problematic behavior. Since pre-kindergarten is the first, more formal school experience, it is noteworthy that bolstering the support these young children received from parents and teachers allowed them to maintain a better status from which learning can occur. 


\section{Limitations}

This study was the first of its kind conducted with both parents and teachers being trained as first order change agents, whereby both were working towards enhancing their relationships with the preschoolers. The hope was that they could assist the students in their efforts to become engaged learners with the tools necessary to succeed in school. Because parents and teachers provided simultaneous intervention to the children, it is impossible to determine whether change was created due to the intervention of the parent, the teacher, or the combined effects of both parent and teacher. A significant limitation of this study was that teachers did not receive the training in an ongoing group format and may not have received enough training to feel competent in the intervention (Solis, 2005). More training for teachers in an ongoing group format would also likely have increased adherence to the program. Kinder Training with teachers in an ongoing group format, as the parents received, might be more effective through drawing on the power of group. Teachers have few chances to interact with each other during the day and would likely benefit from the support and learning that can take place in a group.

The degree to which these measures were sensitive to change is a limitation. The qualitative interview data suggest that more changes were occurring than were evidenced by the quantitative measures. It is important to determine whether there are measures that are more sensitive to behavior changes in this population. It is important to note that since these students were generally not displaying behavioral problems according to rating scales, the margin of improvement would be expected to be smaller. Caution must be maintained when interpreting the findings due to the small sample size of parents, teachers, and students. These findings cannot be generalized to a larger population of preschoolers.

\section{Directions for Future Research}

The results of this study lend partial support for the combined use of Filial Therapy and Kinder Training as an effective brief 
preventative intervention with children in school-based settings who are considered to be broadly at risk for future school or mental health problems. To make definitive conclusions about the efficacy of this intervention, further research is needed in which students are randomly assigned to Filial Therapy only, Kinder Training only, combined Filial Therapy and Kinder Training, another child therapeutic treatment, or a control group. While the combined use of Filial Therapy and Kinder Training in this study served to prevent the development of maladaptive behavior among participating students in the short term, follow-up measures at later dates would be helpful to determine if these gains would be sustained in the long term. Also, further investigation of how factors such as treatment duration, attrition rates, adherence to treatment protocol, and treatment setting impact treatment outcomes is needed. A holistic approach involving teachers and parents as first order therapeutic change agents in children's lives seems to offer promise as a way to strengthen the competencies of not only preschoolers but of parents and teachers too.

\section{Implications for Practice}

The study findings support the conclusions drawn from numerous other play therapy outcome studies (cf. Bratton et al., 2005; LeBlanc \& Ritchie, 2001) that play-based therapy is an efficacious intervention for children considered at risk. The clear implication for practice is that both Filial Therapy and Kinder Training, either separately or in combination seem to have a positive impact on at risk children in terms of preventing a downward trend in their behavior. The literature suggests that positive relationships act as protective factors in children's lives (e.g., Ainsworth, 1973; Bowlby, 1988; Pianta, 1999). The more supports children can harness from adults in positions of influence in their life, the better equipped they will be to weather adversities. Therapists working with children should advocate for the use of non-directed play therapy and for the engagement of parents and teachers in play therapy interventions in school and other settings. Practitioners conducting groups who are comfortable with play therapy and 
parent and teacher consultation may consider adding such structured group interventions to their repertoire.

\section{REFERENCES}

Abidin, R.R. (1995). Parenting Stress Index: Professional manual. 3rd ed. Odessa, FL: Psychological Assessment Resources.

Ainsworth, M.D.S. (1973). The development of infant-mother attachment. In B.M. Caldwell \& H.N. Ricciuti (Eds.), Review of child development research (Vol. III). Chicago: University of Chicago Press.

Armstrong, M.I., Birnie-Lefcovitch, S., \& Ungar, M.T. (2005). Pathways between social support, family well being, quality of parenting, and child resilience: What we know. Journal of Child and Family Studies, 14(2), 269-281.

Axline, V.M. (1947). Play therapy. New York: Ballantine Books.

Barr, R.D., \& Parrett, W.H. (2001). Hope fulfilled for at risk and violent youth K-12 programs that work. Needhorn Heights, MA: Allyn and Bacon.

Bowlby,]. (1988). A secure base: Parent-child attachment and healthy human development. New York: Basic.

Bratton, S.C., Ray, D., Rhine, T., \& Jones, L. (2005). The efficacy of play therapy with children: A meta-analytic review of treatment outcomes. Professional Psychology: Research and Practice, 36(4), 376-390.

Brazelton, T.B., \& Greenspan, S.l. (2000). The irreducible needs of children. Cambridge, MA: Perseus.

Caplan, F., \& Caplan, T. (1973). The power of play. New York: Anchor Books.

Children's Institute (2002). Parent Appraisal of Children's Experiences (PACE 2.0). Rochester, NY: Author.

Draper, K., White,]., O'Shaughnessy, T., Flynt, M., \&Jones, N. (2001). Kinder training: Play-based teacher consultation to improve the school adjustment of discouraged kindergarten and first grade students. International journal of Play Therapy, 10(1), 1-29.

Early, D.M., Maxwell, K.L., Burchinal, M., Bender, R.H., Ebanks, C., Henry, G.T., et al. (2007). Teachers' education, classroom quality, and young children's academic skills: Results from seven studies of preschool programs. Child Development, 78(2), 558-580.

Egeland, B., Carlson, E., \& Sroufe, L.A. (1993). Resilience as a process. Development and Psychopathology, 5, 517-528. 
Ferguson, E.D. (1984). Adlerian theory: An introduction. Vancouver, British Columbia: Adlerian Psychology Association of British Columbia.

Garbarino, J. (1999). Lost boys: Why our sons turn violent and how we can save them. New York: Free Press.

Gil, E. (1991). The healing power of play: Working with abused children. New York: Guilford.

Gladding, S.T. (2003). Group work: A counseling specialty. Upper Saddle River, NJ: Merrill Prentice-Hall.

Goldstein, S., \& Brooks, R.B. (Eds.). ( 2006). Handbook of resilience in children. New York: Springer Science \& Business Media.

Guerney, B.G.,Jr. (1964). Filial therapy: Description and rationale.Jour• nat of Consulting Psychology, 28, 303-310.

Guerney, B. G. (1979). The great potential of an educational skill-training model in problem prevention.journal of Clinical Child Psychol. ogy, 3(2), 84-86.

Guerney, B.G., \& Guerney, L.F. (1988). Building relationship skills in families and para-family teams. In D.H. Olson (Ed.), Family perspec. lives in child and youth services (pp. 49-65). New York: Haworth.

Guerney, B.G. \& Stover, L. (1971). Filial therapy: Final report on $\mathrm{MH}$ 18254-01. University Park: Pennsylvania State University.

Guerney, L. F. \& Gavigan, M.A. (1981). Parental acceptance and foster parents. journal of Clinical Child Psychology, 10(1), 27-32.

Harris, Z.L, \& Landreth, G.L. (1997). Filial therapy with incarcerated mothers: A five week model. International journal of Play Therapy, 6(2), 53-73.

Kale, A., \& Landreth, G. (1999). Filial therapy with parents of children experiencing learning difficulties, International journal of Play Therapy, 8(2), 35-56.

Landreth, G. L. (1991). Play therapy: The art of the relationship. Bristol, PA: Accelerated Development.

Landreth, G.L. (2002). Play therapy: The art of the relationship (2nd ed.) New York: Brunner-Routledge.

Landreth, G.L., \& Bratton, S.C. (2006). Child parent relationship therapy (CPRT): A 10-session filial therapy model. New York: Taylor and Francis.

Landreth, G. L. \& Lobaugh, A.F. (1998). Filial therapy with incarcerated fathers: Effects on parental acceptance of child, parental stress, and child adjustment. journal of Counseling and Development, 76(2), 157-165.

LeBlanc, M., \& Ritchie, M. (2001). A meta-analysis of play therapy outcomes. Counseling Psychology Qyarterly, 14, 149-163. 
Pianta, R.C. (1999). Enhancing relationships between children and teachers. Washington, DC: American Psychological Association.

Reitman, D., Currier, R.O., \& Stickle, T.R. (2002). A critical evaluation of the Parenting Stress Index-Short Form (PSI-SF) in a Head Start population. journal of Clinical Child \& Adolescent Psychology, J/(3), 384-392.

Reynolds, C. R., \& Kamphaus, R. W. (1992). BASC - Behavioral Assessment System for Children Manual. Circle Pines, MN: American Guidance Service.

Sensue, M.E. (1981). Filial therapy follow-up study: Effects on parental acceptance and child adjustment. Dissertation Abstracts Internationa 42(1-A), 148.

Solis, C. (2005). Implementing kinder training as a preventive intervention: African American preschool teacher perceptions of the process, effectiveness, and acceptability. Unpublished doctoral dissertation, Georgia State University.

Sywulak, A. (1977). The effect of filial therapy on parental acceptance and child adjustment. Unpublished doctoral dissertation, Pennsylvania State University.

Tew, K., Landreth, G., Joiner, K., \& Solt, M. (2002). Filial therapy with parents of chronically ill children. International Journal of Play Therapy, 11(1), 79-100.

White,]., Draper, K., \& Flynt, M. (2003). Kinder training: A school counselor and teacher consultation model utilizing an integration of filial therapy and Adlerian theory. In R. VanFleet, \& L. Guerney (Eds.), Casebook of filial therapy (pp. 331-350). Boiling Springs, PA: Play Therapy Press.

White, J., Flynt, M., \& Draper, K. (1997). Kinder therapy: Training teachers as therapeutic agents. International Journal of Play Therapy, 6(2), 33-49.

White, J., Flynt, M., \& Jones, N. (1999). Kinder therapy: An Adlerian approach for training teachers to be therapeutic agents. journal of Individual Psychology, 55, 365-382.

Yalom, I.D., \& Leszcz, M. (2005). The theory and practice of group psycho. therapy (5'h ed.). New York: Basic Books.

Faye Mishna, Ph.D.

University of Toronto,

Factor-Inwentash Faculty of Social Work

246 Bloor Street West

Toronto, Ontario M5S JA1 Canada

£.mail: fmishna@utoronto.ca.
Received: August 30, 2007

Final draft: April 30, 2008

Accepted: May 2, 2008 